Wählen und gewinnen

\section{Ihr liebstes Titelbild?}
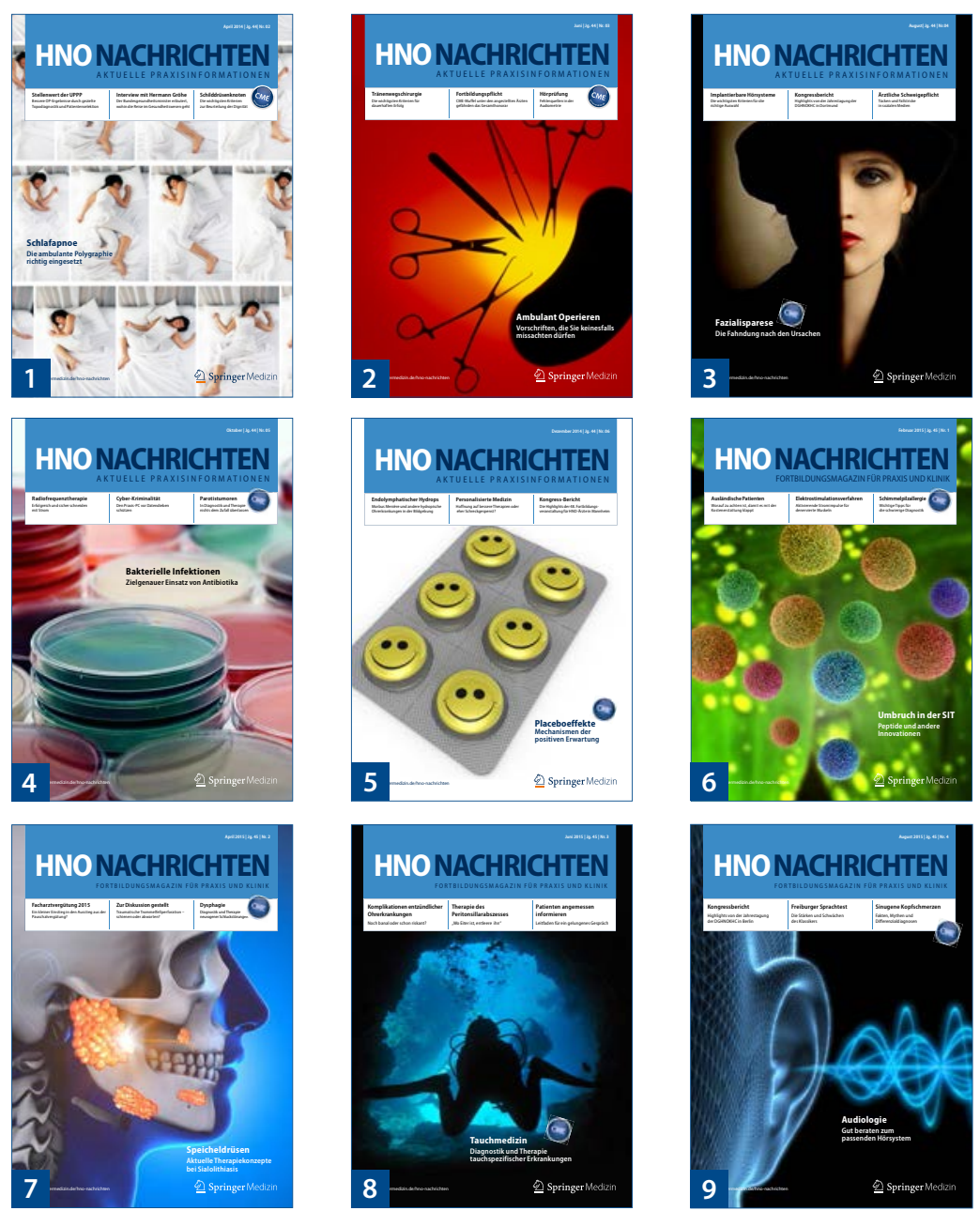

Das können Sie gewinnen

Unter allen Teilnehmern verlosen wir folgende Preise:

1. Preis:

(im Wert von $219 €$, unverbindliche Preisempfehlung) Canon Digital-Kamera Ixus 275 HS: Befunde und Ver-

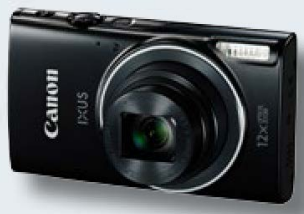
läufe bei Ihren Patienten per Digital-Foto oder HD-Video schnell dokumentieren.

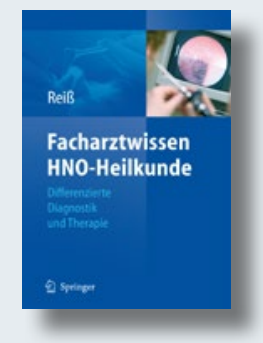

2.Preis: (im Wert von $129,99 €)$ Facharztwissen HNO-Heilkunde Michael Reiß (Hrsg) Springer Verlag

\section{Preis:}

(im Wert von 52,99€)

Stimmdiagnostik

Berit Schneider-Stickler,

Wolfgang Bigenzahn

Springer Verlag

Teilnahme-Coupon bitte ausfüllen und bis zum

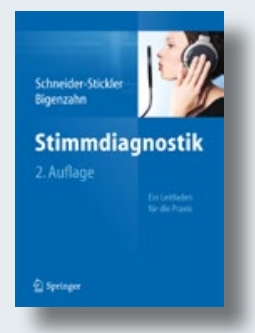

5.2.2016 an die Redaktion faxen: 089-20 3043 32 216. Oder schicken Sie Ihre Auswahl und Ihre Kontaktdaten per Mail an nadine.ziegler@ springer.com.

Die Teilnahme ist unter www.springermedizin. de/gewinnspiel-hno-nachrichten auch online möglich.

Welches der abgebildeten Titelbilder der HNO Nachrichten gefällt Ihnen am besten?
Nr. 1
23
45
6
78

\title{
Name
}

Vorname

Straße

Hausnummer

Postleitzahl

Ort

FAX: 08920304332216

Eine Barauszahlung der Preise ist nicht möglich. Der Rechtsweg ist ausgeschlossen. Mitarbeiter des Verlags dürfen nicht teilnehmen. 